\title{
Portal hypertensive gastropathy after variceal eradication: more bleeding risk or just more reddening?
}

\author{
Massimo Primignani ${ }^{1} \cdot$ Giulia Tosetti $^{1}$
}

Received: 12 April 2016/ Accepted: 27 May 2016/Published online: 9 June 2016

(C) Asian Pacific Association for the Study of the Liver 2016

Portal hypertension may cause mucosal changes in the whole gastrointestinal tract, which may be the source of chronic or, more rarely, acute bleeding. Such changes often involve the stomach and, more rarely, the duodenum or the entire small bowel, and the colon. Major controversies on portal hypertensive gastropathy (PHG) regard its incidence, reported from 7 to $98 \%$ [1-6], the rates of PHG-related acute bleeds, reported from 2.7 to $44.6 \%$ [1, 3, 6, 7], and its evolution after endoscopic treatment of esophageal varices. The last of these topics is addressed in the study by Elwakil et al. [8] recently published in Hepatology International.

Undoubtedly, part of the disagreement depends on the existence of different PHG classifications (Table 1). Ideally, a classification should be simple, as simplicity helps reproducibility, and clinically useful, that is, able to predict clinical events [9]. Unfortunately, none of the current classifications consistently showed to fulfil both criteria.

The most used PHG classifications are those by McCormack et al. [1], the New Italian Endoscopic Classification (NIEC) [10], and the Baveno scoring system [11], but no consensus exists as to which classification should be preferred. Doubts still exist on their reproducibility and on the accuracy of endoscopic features alone in diagnosing PHG. However, as the PHG lesions are mainly located in the submucosa, standard endoscopic biopsies may prove falsely negative, and deep biopsies, with a non-negligible bleeding risk, might be required. These reasons seem to

Massimo Primignani

massimoprimignani@gmail.com

1 Fondazione IRCCS Ca' Granda Ospedale Maggiore Policlinico, Milan, Italy preclude the widespread acceptance of histology to improve the accuracy of PHG classifications.

Moreover, while, in the McCormack and NIEC classifications, the hallmark of PHG is the mosaic-like pattern (MLP) with superimposed red signs to designate severe forms, the Baveno classification also includes gastric vascular ectasia (GVE), defined by the presence of red spots without background MLP, linearly arranged in the antrum or sparsely spread in the distal or proximal stomach. Contrary to MLP, which is frequent in patients with portal hypertension, GVE is rare, being reported in only $2 \%$ of patients listed for liver transplantation [12]. Moreover, GVE has peculiar pathophysiology and histopathological features, which, different from the MLP, do not respond to portal pressure decreasing treatments, such as nonselective $\beta$-blockers or transjugular intrahepatic portosystemic shunts [13, 14]. In addition, whereas MLP changes occur only in patients with portal hypertension, GVE is also found in other conditions such as chronic renal failure, bone marrow transplantation and autoimmune connective tissue disorders $[15,16]$. For these reasons, the inclusion of GVE in a scoring system of PHG may be questioned, although, from a pragmatic point of view, it must be acknowledged that the Baveno scoring system appears to reflect the risk of chronic bleeding in cirrhosis patients [17].

The great variability in the reported rates of acute PHG bleeds is likely due to imprecision in diagnosing PHG as the cause of bleeding in patients also carrying esophageal varices. Such diagnoses, easy when small non-bleeding varices and severe PHG coexist, or easily excluded when mild PHG and large varices occur, are difficult when large varices without evident stigmata of bleeding and severe PHG concur. In such a common situation, the presence of blood in the stomach precludes an accurate visualization of 
Table 1 Classifications for portal hypertensive gastropathy

\begin{tabular}{|c|c|c|}
\hline Authors & Mild & Severe \\
\hline \multirow[t]{3}{*}{ McCormack et al. [1] } & Fine pink speckling ("scarlatina" type rash) & \\
\hline & $\begin{array}{l}\text { Superficial reddening, especially on rugal surface (striped } \\
\text { appearance) }\end{array}$ & $\begin{array}{l}\text { Discrete red spots (analogous to cherry red } \\
\text { spots in esophagus) }\end{array}$ \\
\hline & $\begin{array}{l}\text { Fine white reticular pattern separating areas of raised } \\
\text { oedematous mucosa (snake skin) }\end{array}$ & Diffuse hemorrhagic gastritis \\
\hline \multirow[t]{3}{*}{ Spina et al. [9] (NIEC) } & \multirow{3}{*}{$\begin{array}{l}\text { Mosaic-pattern: Presence of small polygonal areas surrounded } \\
\text { by a whitish-yellow depressed border }\end{array}$} & Red point lesions ( $1 \mathrm{~mm}$ in diameter, flat) \\
\hline & & Cherry-red spots ( $2 \mathrm{~mm}$, slight protrusion) \\
\hline & & $\begin{array}{l}\text { Black-brown spots (irregularly shaped, } \\
\text { persistently present after washing) }\end{array}$ \\
\hline \multirow{6}{*}{$\begin{array}{l}\text { Sarin et al. [10] (Baveno II } \\
\text { Consensus Workshop) }\end{array}$} & PHG Mild $\leq 3$ points & PHG Severe $\geq 4$ points \\
\hline & Mild mucosal mosaic pattern & 1 point \\
\hline & Severe mucosal mosaic pattern & 2 points \\
\hline & Isolated red markings & 1 point \\
\hline & Confluent red markings & 2 points \\
\hline & Gastric Antral Ectasia present & 2 points \\
\hline
\end{tabular}

the gastric mucosa. Given the higher mortality risk carried by an untreated variceal bleed, one should conclude that the variceal source is the likely cause of the actual bleeding and treat it accordingly by band ligation, unless blood oozing from the gastric mucosa is clearly observed. If such a strict criterion to define the source of bleeding is applied, it appears that acute PHG bleeding is rather uncommon.

Keeping in mind these considerations might help to understand why the time evolution of PHG after endoscopic treatment of esophageal varices has received much attention, but has also displayed controversial results in the literature.

Former studies showed that the prevalence of PHG lesions, assessed according to the NIEC classification, was higher in patients with previous or ongoing endoscopic treatment of esophageal varices, either sclerotherapy or band ligation [7], than in untreated patients with comparable disease severity, but the PHG evolution with time was similar, showing stability, worsening, improvement or fluctuations of PHG lesions. Such findings suggested that the higher prevalence of PHG in patients on endoscopic treatment might be a reflection of a more severe portal hypertension or a longer duration of liver disease and not be a consequence of endoscopic therapy per se. However, most of the subsequent studies showed that PHG increased in incidence and that pre-existent PHG increased in severity after eradication of esophageal varices by either sclerotherapy [18] or band ligation [19, 20].

The study by Elwakil et al. [8] evaluates the effect of endoscopic variceal eradication by band ligation on PHG, assessed according to the Baveno scoring system [11], and on portal hypertensive duodenopathy.
The inclusion of histopathological findings, likely less exposed to inter- and intraobserver variation, strengthens the evidence that PHG worsens after band ligation of esophageal varices, and indicates that the histopathological features parallel the endoscopic severity, at least in PHG. In fact, as far as duodenopathy is concerned, only histopathological findings worsen, but endoscopic findings are unchanged.

It is intriguing that the increased Baveno score after variceal eradication was entirely due to the worsening of the endoscopic features recognized as specific for portal hypertension, namely the MLP with red markings, whereas the GVE score did not change. This may imply that variceal eradication by band ligation (but also or even more by sclerotherapy, as observed in other studies) causes changes in the regional venous circulation which might increase the pathogenic mechanisms of PHG. That these mechanisms are inactive on GVE lesions indirectly confirm that GVE, although occurring (rarely) in cirrhosis patients, has a different, though elusive pathophysiology.

Overall, this study adds support to the prevalent opinion that the eradication of esophageal varices increases the incidence and/or the severity of portal hypertensive mucosal changes involving the gastric and duodenal mucosa and possibly the entire gastrointestinal tract. Yet, we must keep in mind that PHG can spontaneously improve, progress or fluctuate with time, [7] confounding the impact of band ligation or sclerotherapy on PHG.

More important, some studies on this issue [18-20] suggest that the assumed progression of PHG after endoscopic variceal sclerotherapy [18] or band ligation [19, 20] is transient. In particular, the PHG changes occurring "de novo" after sclerotherapy appear to be mild and transient, 
thus entailing a negligible bleeding risk, whereas pre-existing PHG lesions more often persist or progress after variceal eradication by sclerotherapy [18].

Whether such persistent or progressive changes entail an increased bleeding risk from PHG, although not addressed in prospective studies, has been deemed as likely, particularly in the presence of diffuse, severe lesions, thus suggesting the prophylactic addition of nonselective $\beta$ blockers [18].

Band ligation,which shortly achieves variceal eradication, with a lower incidence of adverse events, is the current endoscopic therapy for esophageal varices. Whether the time course of PHG detailed for sclerotherapy is also valid for band ligation was addressed by Hou et al. [19], who reported that the increased severity of PHG after variceal obliteration was transient. Another study [20], assessing the effects of band ligation with or without propranolol on PHG, also showed that band ligation transiently worsens PHG, which is partly relieved by propranolol.

Actually, in the study by Elwakil et al. [8], the presence and severity of PHG and duodenopathy were recorded at baseline and, once only, 4 weeks after variceal eradication, so that the assessment of its evolution with time was limited. Therefore, the possibility that "de novo" PHG changes provoked by band ligation are transient was not explored.

However, the central question refers to the impact of endoscopic techniques, and particularly of the one currently used, on relevant clinical outcomes, namely PHGrelated acute or chronic bleeding, rather than on endoscopic or even histopathological findings. Is this still an unsolved issue? Indeed, no clinical data support that either sclerotherapy or band ligation increase the rate of acute PHG-related bleeding.

As far as chronic bleeding is concerned, we must recall that several causes of anemia in advanced cirrhosis occur. Even when strict criteria are adopted to define chronic blood loss (i.e. a drop in hemoglobin of $2 \mathrm{~g} / \mathrm{dl}$ in 3 months and the presence of occult blood in the stool) it is often difficult to recognize PHG as the cause of anemia, as other lesions due to portal hypertension may coexist along the gastrointestinal tract.

In summary, data from the literature on PHG-related clinical events are highly variable, due to differences in PHG classification and possible misinterpretation of the endoscopic findings. The study by Elwakil et al. supports the view that PHG worsens after band ligation, and identifies large esophageal varices and Baveno score $>1$ at baseline endoscopy as predictors of severe portal hypertensive gastropathy (and duodenopathy) after variceal eradication. However, whether such findings really impact on robust clinical outcomes, such as acute or chronic PHGrelated bleeding, is still unanswered. Therefore, to the question whether we should change the duration of followup endoscopy after esophageal variceal eradication by band ligation in this subset of patients, as they are more prone to develop severe PHG, we can cautiously answer no. Many of these patients probably have a more advanced disease and could benefit from additional treatment with nonselective $\beta$-blockers. Many of them could have experienced previous variceal bleeding, for which a combined treatment with band ligation and $\beta$-blockers is definitively recommended. Finally, as non-selective $\beta$-blockers are protective against PHG-related bleeding [21, 22], their use could be considered, although still not properly addressed in clinical studies, in patients with a Baveno score $>1$ (i.e., MLP with superimposed red signs and/or GVE) and large esophageal varices before prophylactic band ligation, as recognized in the study by Elwakil et al. [8]. In case of intolerance or contraindications to $\beta$-blockers, closer clinical rather than endoscopic follow-up should be recommended.

\section{Compliance with ethical standards}

Conflict of interest Dr. Massimo Primignani declares that he has no conflict of interest. Dr. Giulia Tosetti declares that she has no conflict of interest.

Ethical approval This article does not contain any studies with human participants or animals performed by any of the authors.

\section{References}

1. McCormack TT, Sims J, Eyre-Brook I, Kennedy H, Goepel J, Johnson AJ, Triger DR. Gastric lesions in portal hypertension: inflammatory gastritis or congestive gastropathy? Gut 1985;26:1226-1232

2. Sarin SK, Misra SP, Singal A, Thorat V, Broor SL. Evaluation of the incidence and significance of the "mosaic pattern" in patients with cirrhosis, noncirrhotic portal fibrosis, and extrahepatic obstruction. Am J Gastroenterol 1988; 83:1235-1239

3. D’Amico G, Montalbano L, Traina M, Pisa R, Menozzi M, Spano' C, Pagliaro L, and the liver study group of V. Cervello Hospital. Natural history of congestive gastropathy in cirrhosis. Gastroenterology 1990; 99:1558-1564

4. Cales P, Zabotto B, Meskens C, Caucanas JP, Vinel JP, Desmorat H, Fermanian J, Pascal JP. Gastroesophageal endoscopic features in cirrhosis. Observer variability, interassociations, and relationship with hepatic dysfunction. Gastroenterology 1990; 98:156-162

5. Sarin SK, Sreenivas DV, Lahoti D, Saraya A. Factors influencing development of portal hypertensive gastropathy in patients with portal hypertension. Gastroenterology 1992; 102:994-999

6. Gostout CJ, Viggiano TR, Balm RK. Acute gastrointestinal bleeding from portal hypertensive gastropathy: prevalence and clinical features. Am J Gastroenterol 1993; 88:2030-2033

7. Primignani M, Carpinelli L, Preatoni P, Battaglia G, Carta A, Prada A, Cestari R, Angeli P, Gatta A, Rossi A, Spinzi G, De Franchis R. Natural history of portal hypertensive gastropathy in patients with liver cirrhosis. The New Italian Endoscopic Club for the study and treatment of esophageal varices (NIEC). Gastroenterology 2000; 119(1):181-187 
8. Elwakil R, Al Breedy AM, Gabal HH. Effect of endoscopic variceal obliteration by band ligation on portal hypertensive gastroduodenopathy: endoscopic and pathological study. Hepatol Int 2016; doi:10.1007/s12072-016-9711-z (Epub ahead of print)

9. Soares de Macedo GF, Gonçalves Ferreira F, Alves Ribeiro M, Szutan LA, Saab Assef M, Rossini GB. Reliability in endoscopic diagnosis of portal hypertensive gastropathy. World J Gastrointest Endosc. 2013; 16; 5(7):323-31

10. Spina GP, Arcidiacono R, Bosch J, Pagliaro L, Burroughs AK, Santambrogio R, Rossi A. Gastric endoscopic features in portal hypertension: final report of a consensus conference, Milan, Italy, September 19, 1992. J Hepatol 1994; 21:461-467

11. Sarin SK. Diagnostic issues: Portal hypertensive gastropathy and gastric varices. In: De Franchis R, editor. Portal hypertension II. Proceedings of the second Baveno international consensus workshop on definitions, methodology and therapeutic strategies. Oxford: Blackwell, 1996:30-55

12. Ward EM, Raimondo M, Rosser BG, Wallace MB, Dickson RD. Prevalence and natural history of gastric antral vascular ectasia in patients undergoing orthotopic liver transplantation. J Clin Gastroenterol 2004; 38:898-900

13. Spahr L, Villeneuve JP, Dufresne MP, Tassé D, Bui B, Willems B, Fenyves D, Pomier-Layrargues G.. Gastric antral vascular ectasia in cirrhotic patients: absence of relation with portal hypertension. Gut 1999; 44:739-42

14. Kamath PS, Lacerda M, Ahlquist DA, McKusick MA, Andrews JC, Nagorney DA. Gastric mucosal responses to intrahepatic portosystemic shunting in patients with cirrhosis. Gastroenterology 2000; $118: 905-11$
15. Tobin RW, Hackman RC, Kimmey MB, Durtschi MB, Hayashi A, Malik R, McDonald MF, McDonald GB. Bleeding from gastric antral vascular ectasia in marrow transplant patients. Gastrointest Endosc 1996; 44:223-229

16. Ingraham KM, O'Brien MS, Shenin M, Derk CT, Steen VD. Gastric antral vascular ectasia in systemic sclerosis: demographics and disease predictors. J Rheumatol 2010; 37:603-607

17. Stewart CA, Sanyal AJ. Grading portal gastropathy: validation of a gastropathy scoring system. Am J Gastroenterol 2003; 98:1758-1765

18. Sarin SK, Shahi HM, Jain M, Jain AK, Issar SK, Murthy NS. The natural history of portal hypertensive gastropathy: influence of variceal eradication. Am J Gastroenterol 2000; 95:2888-2893

19. Hou MC, Lin HC, Chen CH, Kuo BI, Perng CL, Lee FY, Lee SD. Changes in portal hypertensive gastropathy after endoscopic variceal sclerotherapy or ligation: an endoscopic observation. Gastrointest Endosc 1995; 42:139-144

20. Lo GH, Lai KH, Cheng JS, Hsu PI, Chen TA, Wang EM, Lin CK, Chiang HT. The effects of endoscopic variceal ligation and propranolol on portal hypertensive gastropathy: a prospective, controlled trial. Gastrointest Endosc 2001; 53:579-584

21. Hosking SW, Kennedy HJ, Seddon I, Triger DR. The role of propranolol in congestive gastropathy of portal hypertension. Hepatology 1987; 7:437-441

22. Perez-Ayuso RM, Pique JM, Bosch J, Panes J, Gonzalez A, Perez $\mathrm{R}$, et al. Propranolol in prevention of recurrent bleeding from severe portal hypertensive gastropathy in cirrhosis. Lancet 1991; 337:1431-1434 